\title{
Selling Our Southern Skies: recent public astronomy developments at the Carter Observatory, New Zealand
}

\author{
By W. Orchiston, B. Carter, R. Dodd \& R. Hall \\ Carter Observatory, PO Box 2909, Wellington, New Zealand (Wayne.Orchiston@vuw.ac.nz)
}

\section{Introduction}

Carter Observatory is the gazetted National Observatory of New Zealand, and opened in 1941 December. From the start, the main function of the Observatory was to provide for the astronomical needs of the citizens of, and visitors to, the Wellington region, and today this remains one of its four recognised functions (Orchiston and Dodd, 1995). The other three are to conduct astronomical research of international significance; provide a national astronomy education service for school students, teachers, and trainee teachers; and assist in the preservation of New Zealand's astronomical heritage.

Since 1992 the Carter Observatory has undergone major restructuring as a result of acquiring an aging Zeiss planetarium and an accompanying visitor centre (Van Dijk, 1992), and in response to major changes in Government funding policy. As a result, there has been a wholesale revamp of the education and public astronomy functions (see Orchiston, 1995b; Orchiston and Dodd, 1996). This paper focuses on the latter area, with emphasis on development of the Visitor Centre and the publications program.

\section{The Visitor Center}

The focal point of the Observatory's in-house public astronomy programs is the Visitor Centre, comprising a foyer area with "Space Shop", the planetarium chamber, an audiovisual theatre (that also doubles as a meeting room), a small video room which also houses a public-access PC (featuring the "Orbits"program), and the "Dome Room" where the Observatory's historically-significant $23 \mathrm{~cm}$ Cook photovisual refractor (see Andrews and Budding, 1992; Orchiston et al., 1995) holds pride of place. There are also the mandatory wheelchair-access toilets, and adjacent to the theatre is a small kitchen.

Access to the Visitor Centre is not a problem for most visitors using public transport, since the Carter Observatory is only a short distance from downtown Wellington and can be reached by bus or cable car. Those coming by private car face more of a challenge, given the lack of public car parking nearby. Adequate external signage is vital for any public facility, and in this regard the Carter Observatory is now well provided for. At nearby entrances to the Wellington Botanic Garden there are large colourful maps and conspicuous signposting indicating the location of the Observatory, and this information is also readily available in brochure form.

In order to create an attractive "astronomical environment" in the Visitor Centre the walls and ceiling of the foyer have been painted black, and external lighting has been minimised (except for the large "shop front" window near the entrance doorway) so that beamed spotlights can have maximal effect. The astronomical mood is further enhanced by the attractive astronomical murals that have been painted on the foyer walls and ceiling by one of the authors (R.H.), while panel displays feature in the audio-visual theatre.

In addition to providing an accessible, warm, friendly astronomical environment, we 
aim whenever possible to supply our visitors with background information which will help them optimise the benefits of a visit. This is achieved by giving every visitor a single A4 Visitor Orientation Sheet, which contains a list of what there is to see and do in the Visitor Centre; a map of the Centre; and background information about the Carter Observatory and the Observatory's Golden Bay Planetarium. We have made full use of the monthly statistics on overseas visitors to New Zealand supplied by the New Zealand Tourism Board, and now have Visitor Orientation Sheets in the following languages: English, Chinese (two different dialects), German, Japanese, and Korean. In the 1995 calendar year, native-speakers using these languages accounted for over $90 \%$ of the 1.4 million overseas visitors to New Zealand.

When the Carter Observatory was presented with the Zeiss planetarium facility by the Wellington Planetarium Society in 1992 it also inherited a number of thematic planetarium programs made during the 1970 s and early 80 s. A special challenge for Observatory staff has been to produce new up-to-date programs, and since the end of 1993 four have been completed. Brief accounts of the first three appear in Orchiston and Dodd, 1996. With previous experience to draw on and extensive feedback from the public, in 1996 the "Project Team" decided to embark on a major refurbishment of the planetarium chamber prior to the launch of the most recent program, "Journey to the Centre of the Galaxy". As a result, the projection system for the seven slide projectors was altered to make use of just half of the dome, and lap-dissolved images from two IMAX-type lenses were beamed onto the same dome space (instead of opposite one another, as previously). The seating configuration in the planetarium chamber was also extensively modified to accommodate this new unidirectional projection system; the speakers were relocated in order to provide an improved sound system; the interior surface of the $6 \mathrm{~m}$ dome was resealed and repainted; and a light-free "tunnel" was constructed leading from the darkened planetarium chamber to the illuminated visitor centre foyer (thereby, if necessary, allowing people to leave during a screening without disrupting other patrons).

A major facility in the foyer is the "Space Shop" which has grown since 1992 to encompass a wide range of stock for the following specific "target audiences": general public, school students, teachers and trainee teachers, amateur astronomers, and overseas tourists (but particularly those from northern hemisphere countries). In addition to books, booklets and pamphlets, the shop has a good selection of posters, cards, post cards (both astronomical and non-astronomical), astronomical jewellery, holographic products, and educational products (e.g. kits, computer programs, sky globes). There are also tektites for sale, and the following special Carter Observatory stock lines: ball point pens, "astrofrogs" (novelty gifts), and T-shirts and sweat shirts. Also available, on compact disk, is the original background music composed especially for our latest planetarium program by an amateur astronomer who works professionally in the music industry.

Shop product is sourced both from within New Zealand and overseas, and staff are always on the lookout for suitable new stock lines. Perceived popularity, quality, and calculated retail price are key selection criteria. Considerable shop revenue is generated through the Observatory's Summer and Winter Mail Order Catalogues which we generate in-house. These now run to $14 \mathrm{~A} 5$ pages, and are distributed to schools, libraries, astronomical societies and individual amateur and professional astronomers.

\section{Carter Observatory Publications}

One of the most notable developments in public astronomy at the Carter Observatory since 1993 has been the in-house publications strategy. The aim has been to provide different types of publications for different perceived target audiences. This involved 
modifying the existing publications, introducing new types of publications, and (for purposes of product branding and marketing) adopting a "house style". A black cover with white print was selected as "astronomically- appropriate", but this is relieved by a feature coloured image on the front cover and a coloured photograph of the Observatory itself on the back cover.

The annual Astronomical Handbook, which has been in production since 1972, was one of the first publications to undergo wholesale change, in 1994. A new cover, with an astrophotograph of the Great Orion Nebula by award-winning New Zealand amateur astronomer, John Drummond, replaced the former monochrome cover, while the range of astronomical data inserted was drastically changed. A further innovation was the introduction of an "Articles Section" along the lines of that in Patrick Moore's annual Yearbook of Astronomy. The first "new look" Handbook ran to 72 pages (up from the previous 48 pages), while additional astronomical information and an enlarged Articles Section extended the 1996 issue to 132 pages.

The aim with the Articles Section has been to provide a range of topics, but with some emphasis on New Zealand astronomy, and to include at least one article per issue by a noted overseas astronomer. The 1995 Handbook contained six articles ranging in length from 4 to 10 pages, while the seven articles in the 1996 issue were between 6 and 11 pages long. Patrick Moore and Duncan Steel (Anglo-Australian Observatory) featured in the 1995 edition, while Heather Couper and Andrew Taylor (University of Adelaide) have articles in the 1996 Handbook. Although now resident in Australia, both Steel and Taylor completed their Ph.D.'s in New Zealand. At just $\$$ NZ9:95 (plus postage, if necessary), we believe that the 1996 Handbook represents exceptional value for money.

Another existing publication to undergo a drastic revamp was the Annual Report, starting with the 1993-94 issue. Again, the "house style" was adopted, and the contents were restructured. More line drawings and half-tones were introduced, making this publication more "user friendly" for amateur astronomers, funding bodies, potential corporate sponsors, and Government officials. The 1993-94 Annual Report ran to 38 pages, while the 1994-95 issue was 48 pages long.

In order to provide cheap, readily-available and up-to-date information for the general public, overseas visitors, school students and New Zealand amateur astronomers, the Carter Observatory introduced its Information Sheet series in 1993. To date, 16 different Information Sheets have been generated (Table 1), and these A4 photocopied in-house publications range from 2 to 10 pages in length. Given the paucity of authoritative books and research papers on New Zealand astronomy, the historically-oriented Information Sheets have proved particularly valuable for they provide the most detailed accounts available - indeed, sometimes the only accounts available - on particular aspects of our astronomical history and heritage. Meanwhile, second editions are currently being prepared of Information Sheets 6 and 11, where the changing state of our knowledge has rendered the original versions obsolete.

A new publication pioneered in 1996 May was a monthly Carter Observatory Newsletter. This A4 publication runs to just 8 pages, and contains information on the night sky, the Observatory's current public astronomy and education programs, general Carter Observatory news, and summaries of selected material from recent IAU Circulars and astronomical magazines and journals. By pooling this information, the Newsletter brings together material that three different staff members were assembling monthly for the media, the Wellington region's five visitor information centres, and for two different astronomical society newsletters. The Carter Observatory Newsletter is now supplied free of charge to New Zealand astronomical societies, and they are encouraged to reproduce any material of interest in their own newsletters (with due acknowledgement). Mean- 
while, individuals, libraries and schools who wish to subscribe to the Carter Observatory Newsletter pay an annual fee of \$NZ36.

Other types of Carter Observatory publications are planned, and the first monograph in the Carter Observatory Occasional Papers series is in active preparation.

Table 1: Carter Observatory Information Sheets

\begin{tabular}{rrlr}
\hline No. & Year & Title & Pages \\
\hline 1 & 1995 & A Brief History of the Carter Observatory & 10 \\
2 & 1993 & $\begin{array}{l}\text { Coming to Terms with Size, Time and Distance in } \\
\text { Astronomy }\end{array}$ & 4 \\
3 & 1993 & John Grigg: New Zealand's Pioneer Cometary Astronomer & 4 \\
4 & 1993 & A Guide to Purchasing Telescopes and Binoculars & 8 \\
5 & 1993 & Careers in Astronomy in New Zealand & 2 \\
6 & 1994 & The Quest for the Elusive Tenth Planet & 4 \\
7 & 1994 & The Enigma of the Tektites & 2 \\
8 & 1994 & The Southern Cross: Our Very Own Constellation & 4 \\
9 & 1994 & James Cook and the 1769 Transit of Mercury & 4 \\
10 & 1994 & Ronald McIntosh: A Remarkable New Zealand Astronomer & 4 \\
11 & 1994 & Worlds in Collision: Comet Shoemaker-Levy 9 and Jupiter & 2 \\
12 & 1995 & The Historic Astronomical Observatories in the Wellington & 8 \\
& & Botanic Garden: A Brief Introduction & 6 \\
13 & 1995 & A History of the 23cm Refracting Telescope at the Carter & 4 \\
14 & 1995 & Charles Rooking Carter: A Brief Biography & 2 \\
15 & 1995 & Is There Water in Space? & 4 \\
16 & 1996 & The Enigmatic "Uncle Charlie": Algernon Charles Gifford & \\
\hline
\end{tabular}

\section{Other Public Program Initiatives}

In addition to the foregoing developments, in 1994 Carter Observatory staff began producing 30-minute thematic audio-visual shows, using two slide projectors and a tape with commentary, sound effects and background theme music. Two shows have been prepared to date: "Galileo: A Space Odyssey", and "Ra: God of Light". Wide-angle lenses on the slide projectors throw $4 \mathrm{~m}$ by $2.4 \mathrm{~m}$ images onto the end wall of the audio-visual theatre. But despite their obvious visual appeal, on twice-weekly "Public Nights" the video screenings, audio-visual show and two different planetarium programs do not usurp the rightful place of sky-viewing through the 23-cm telescope, for we believe that visitors if possible should also see "the real thing"(c.f. Bell, 1993 and Mullaney, 1993).

Another significant development since 1993 has been the establishment of three different monthly radio programs. Two of these, of 15 minutes and 30 minutes duration, are beamed locally, while the third program (also of 15 minutes duration) goes out nationally. On all three programs we provide astronomical news (often with a New Zealand focus) and "Sky for the Month". Fortunately, we have not had to find sponsorship for any of these programs. As a spin-off from these high-profile presentations, Observatory staff are increasingly appearing on local and national television. 
Another high-profile innovation is the annual Carter Memorial Lecture series. Launched in 1993 with New Zealand's most distinguished space scientist, Sir Ian Axford as speaker (see Orchiston, 1995a), this series aims to provide New Zealanders with up-to-date information by talented speakers of international repute. The 1995 Lecturer was Professor Heather Couper, and she presented Carter Memorial Lectures at five different New Zealand centres. Meanwhile, former Astronomer Royal, Sir Arnold Wolfendale, delivered the 1996 Carter Memorial Lecture in Wellington, and as with both of his predecessors attracted a capacity audience of around 300 .

Finally, the Observatory has sought to take its message to a diverse national and international audience through the World Wide Web. In late-1995, Dr Timothy Banks (Research Associate) and one of the authors (W.O.) established a Home Page containing wide-ranging information about the Observatory, its staff and its activities. During the first six months interest increased dramatically, and as at 1996 June the number of accesses was $>3,500$ per month from around the world. Our Home Page address is:

http://www.vuw.ac.nz/ bankst/carter.html

\section{Discussion}

A major problem, and one which is seen to typify many much larger institutions (e.g. see Griffen, 1993), is the totally inadequate space available in our Visitor Centre, and the current functional mix is a necessary compromise. In the three years from 1992, visitor numbers have trebled from 11,495 to 33,038 , and the visitor "saturation point" has been reached. In the long run, it is vital that the Visitor Centre is expanded to provide discrete spaces for public astronomy and education, and increase the range of options available to visitors. Specifically, we require an interactive display gallery, space for a program of changing mini-displays, and a microcomputer gallery with a range of different software packages. Because of funding restrictions, it is unlikely that this program of expansion will occur in the foreseeable future, and so the challenge now is to make the best possible use of the minimal facilities and the limited staff and funding at our disposal. Our focus, therefore, will be on continuing to produce captivating, visually-appealing, instructive new planetarium programs and audio-visual shows, and increasing the number and range of in-house publications. We also recognise the didactic value of well-prepared displays (see Fierro, 1994), and another short-term objective is to develop a major display on astronomy in New Zealand. When funding becomes available, we would also like to begin making our own videotapes with a specifically New Zealand or southern sky slant.

\section{Conclusion}

Carter Observatory has undergone a major revitalisation since 1992, and now offers a wide-ranging public astronomy program which targets a number of discrete audience sectors. Further developments are planned as additional funding comes to hand.

\section{Acknowledgements}

We are grateful to the British Council and the International Astronomical Union for grants which made it possible for the one of us (W.O.) to visit London and present this paper at IAU Colloquium 162.

\section{REFERENCES}

Andrews,F.P., \& Budding,E.,1992. Carter Observatory's 9-inch refractor: the Crossley connection. Southern Stars 34:358-366. 
BeLl,J.U.,1993. Live vs. video. The Planetarian, 22(3); 24-25,32.

FiERro,J.,1994. Getting started: an astronomy hall for a science museum, Teaching of Astronomy in Asian-Pacific Region, 8, 1-15.

Griffen,I.,1993. Armagh goes for gold in its silver year. Astronomy Now, 7(9), 39-42.

MaLlEY,M.,1993. The Carter Observatory Library. Southern Stars, 35, 110-111.

Mullaney,J.,1993. The role of the telescope in the planetarium. The Planetarian 22(3), 6-7.

Orchiston, W.,1995a. Dr William Ian Axford 1995 "New Zealander of the Year". Australian Journal of Astronomy, 6, 75-79.

,$- 1995 \mathrm{~b}$, Public astronomy and education at the Carter Observatory: some recent developments, In Orchiston,W., Carter,B., and Dodd,R.eds. Astronomical Handbook for 1996, Wellington, Carter Observatory, 59-69.

-, and Dodd,R.,1995. A Brief History of the Carter Observatory, Carter Observatory Information Sheet No. 1, Wellington.

-, and - 1996, Education and public astronomy programs at the Carter Observatory: an overview, Publications of the Astronomical Society of Australia, 13, 165-172.

-, Andrews,F. \& Budding,E.,1995. A History of $23 \mathrm{~cm}$ Refracting Telescope at the Carter Observatory, Carter Observatory Information Sheet No. 13.

VaN DiJK,G.,1992.The New Zealand Astronomy Centre. Southern Stars, 34, 403-406. 